\title{
Evaluation of the Impact of Acidic Drink on the Microhardness of Different Esthetic Restorative Materials: An In Vitro Study
}

\author{
Shabna Moyin ${ }^{1}$, Banibrata Lahiri ${ }^{2}$, George Sam $^{3}$, Preethi Nagdev ${ }^{4}$, Neelagiri Nitish Kumar ${ }^{5}$
}

\begin{abstract}
Aim: The aim of this study was to assess the impact of acidic drink on the microhardness of different esthetic restorative materials.

Materials and methods: Sixty samples (20 samples of each group) were prepared. group I: nanohybrid ormocer-based composite, group II: glasiosite compomer, and group III: nanoceramic composite. A cylindrical aluminum mold of $5 \mathrm{~mm}$ depth and $10 \mathrm{~mm}$ internal diameter was used to prepare the samples. All the esthetic restorative samples were submerged in $25 \mathrm{~mL}$ of acidic drink (Coca-Cola) for 10 minutes each day up to 15 days. The microhardness of each sample was measured using a Vickers diamond intender. These values were matched with baseline, 7 th day, and 15 th day for final microhardness values.

Results: The mean surface microhardness of $61.13 \pm 0.82$ was shown by group I, which was slightly more than that in group II (59.65 \pm 1.16$)$ and group III (59.22 \pm 1.30$)$. Analysis of covariance did not show any statistically significant difference between the groups. The samples in group III showed the highest reduction in surface microhardness value after immersion into acidic drink, followed by group II and group I on 7th day and 15 th day. A statistically significant difference $(p<0.001)$ was found on 7 th day.

Conclusion: The present study concludes that the esthetic restorative material—nanohybrid ormocer-based composite—showed the finest behavior both before and after being dipped in the acidic drink followed next by glasiosite compomer and nanoceramic composite.

Clinical significance: The various esthetic restorative materials with different physical characteristics and colors are marketed in numerous ways. Nevertheless, all dental restorative materials show surface degradation under acidic conditions over a period of time. So, it helps to know the surface microhardness changes of various esthetic restorative materials upon repeated exposure to acidic beverages.

Keywords: Acidic drink, Erosion, Esthetic restorative materials, Surface microhardness.

The Journal of Contemporary Dental Practice (2020): 10.5005/jp-journals-10024-2753
\end{abstract}

\section{INTRODUCTION}

The quest for the best esthetic restorative material has led to sizable advances in discovery of esthetic materials and restorative techniques for using them. Composite resin, the proven excellent esthetic material has been improved pertaining to the resin matrix and filler. ${ }^{1}$

Dental erosion is a chemical process characterized by irreversible loss of localized dental hard tissue by acid and/or chelation without bacterial involvement. This regressive alteration of tooth may be caused by either intrinsic or extrinsic agents. ${ }^{2}$

The intrinsic causes include cytostatic drug treatment, frequent vomiting seen in patients with anorexia and bulimia, or patients suffering from gastroesophageal reflux. Extrinsic causes comprise use of acidic hygiene products and acidic medicines, such as aspirin or effervescent vitamin $\mathrm{C}$ and regular intake of acidic drinks or foods. The $\mathrm{pH}$ of oral cavity falls below the critical $\mathrm{pH} 5.5$ following the intake of acidic juices, soft drinks, and sport drinks eventually leading to demineralization of enamel and dentin. At present, dental erosion is an important oral health problem seen in school-going children and young adults. ${ }^{3}$

The glass ionomer cement, which is conventionally used in dental clinics is a fluoride-releasing biocompatible restorative material that bonds chemically with the prepared tooth cavities; nonetheless, it demonstrates an esthetic limitations, reduced physical strength, and water sensitivity. In order to enhance the mechanical and physical properties of conventional glass ionomer cement (CGIS), compomers have been developed that resemble
${ }^{1}$ Department of Conservative Dentistry and Endodontics, Sree Anjaneya Institute of Dental Sciences, Calicut, Kerala, India

${ }^{2}$ Department of Oral and Maxillofacial Surgery, Kalinga Institute of Dental Sciences, KIIT (Deemed to be University), Bhubaneswar, Odisha, India

${ }^{3}$ Department of Preventive Dental Sciences, College of Dentistry, Prince Sattam Bin Abdul Aziz University, Alkharj, Kingdom of Saudi Arabia

${ }^{4}$ Department of Public Health Dentistry, SJM Dental College and Hospital, Chitradurga, Karnataka, India

${ }^{5}$ Department of Conservative Dentistry and Endodontics, Sri Balaji Dental College and Hospital, Moinabad, Hyderabad, Telangana, India

Corresponding Author: Shabna Moyin, Department of Conservative Dentistry and Endodontics, Sree Anjaneya Institute of Dental Sciences, Calicut, Kerala, India, Phone: +91 9526227454, e-mail: mshabna95@ gmail.com

How to cite this article: Moyin S, Lahiri B, Sam G, et al. Evaluation of the Impact of Acidic Drink on the Microhardness of Different Esthetic Restorative Materials: An In Vitro Study. J Contemp Dent Pract 2020;21(3):233-237.

Source of support: Nil

Conflict of interest: None

composite resin, but the fluoride is released through hybrid materials. ${ }^{4}$ Compomers contain hydroxylethylmethacrylate, and

() The Author(s). 2020 Open Access This article is distributed under the terms of the Creative Commons Attribution 4.0 International License (https://creativecommons. org/licenses/by-nc/4.0/), which permits unrestricted use, distribution, and non-commercial reproduction in any medium, provided you give appropriate credit to the original author(s) and the source, provide a link to the Creative Commons license, and indicate if changes were made. The Creative Commons Public Domain Dedication waiver (http://creativecommons.org/publicdomain/zero/1.0/) applies to the data made available in this article, unless otherwise stated. 
this makes them less biocompatible than CGIS. Of late, giomers have been presented as a substitute for direct restorative procedures. Giomers are biocompatible, polishable, highly esthetic, fluoridereleasing restorative materials. Even though there are many choices for restorative procedures, the ideal material has not been found yet. And it has been reported that a low $\mathrm{pH}$ in acidic drink induces erosive wear in materials. Acidic drink containing carbonic acid and phosphoric acid promotes dissolution, and it easily erodes the esthetic materials. ${ }^{5}$ Hence, the present study was conducted to assess the effect of acidic drink on the microhardness of different esthetic restorative materials.

\section{Materials and Methods}

This in vitro study was conducted in the Department of Conservative Dentistry and Endodontics, Sree Anjaneya Institute of Dental Sciences, Kerala.

A total of 60 composite resin samples (20 composite resin samples of each group) were prepared.

Group I: nanohybrid ormocer-based composite (Admira Fusion, Voco, Cuxhaven, Germany),

Group II: glasiosite compomer (VOCO, Cuxhaven, Germany)

Group III: nanoceramic composite (Ceram X Universal, Dentsply De Trey, Konstanz, Germany).

\section{Preparation of Samples}

About 20 samples of each restorative material were prepared using a cylindrical aluminum mold of $5 \mathrm{~mm}$ depth and $10 \mathrm{~mm}$ internal diameter (Fig. 1). Vaseline was applied on the internal surface of each mold to facilitate easy recovery of the samples. The restorative materials were covered on the top and bottom surfaces with polyester matrix strips (Mylar Strips) and a thin rigid glass slide so as to obtain a flat and uniform polymerized surface without any bubbles after curing. Finger pressure was applied on the glass slide to remove excess material. A light-emitting diode (LED) light was used to a curing unit to polymerize the restorative materials for 20 seconds through the glass slide and polyester matrix strip (Fig. 2). The light probe tip was held at right angles and in contact with the glass slide so as to warrant uniform curing standardized at a distance of $1 \mathrm{~mm}$ between the restorative material and light source. To ensure complete polymerization, all the light cured specimens were kept in a light proof container having distilled water at $37^{\circ} \mathrm{C}$ for 24 hours.

\section{Immersion of Samples in Acidic Drink}

All the samples of different esthetic restorative materials were submerged in $25 \mathrm{~mL}$ of acidic drink (Coca-Cola) for 10 minutes each day up to 15 days.

\section{Evaluation of Surface Microhardness}

A tissue paper was used to blot-dry the samples completely, and the baseline surface microhardness was measured. The microhardness of each restorative sample was measured using a Vickers diamond intender (HMG-G; Shimadzu, Kyoto, Japan) (Fig. 3) just before immersion, and 7th and 15th day after immersion of restorative materials in tested acidic drink. The microhardness reading was measured according to the protocol tested by Yanikoğlu et al. ${ }^{6}$ using a force of $10 \mathrm{~g}$ visible surface of specimen for 15 seconds. The baseline microhardness (Vickers hardness number, VHN1) was measured after taking three consecutive readings and their arithmetic mean. Soon after recording the baseline measurements, the samples were submerged in the beverage. The immersion schedule was as follows: the samples from each restorative group were dipped every day in the beverage for 10 minutes. For the leftover part of the day, the samples were submerged in artificial saliva solutions as follows: $0.2 \mathrm{mmol} / \mathrm{L} \mathrm{MgCl}_{2}, 4.0 \mathrm{mmol} / \mathrm{L} \mathrm{KH}_{2} \mathrm{PO}_{4}, 0.7 \mathrm{mmol} / \mathrm{L} \mathrm{CaCl}_{2} \cdot 2 \mathrm{H}_{2} \mathrm{O}$, $20.0 \mathrm{mmol} / \mathrm{L}$ HEPES [4-(2-hydroxyetyhl)-1-piperazine ethanesulfonic acid] buffer, and $30.0 \mathrm{mmol} / \mathrm{L} \mathrm{KCl}$. This schedule was followed up to 15 days. At the end of the immersion schedule/ test period, the average was calculated for three readings of microhardness (VHN2) of each sample using a method similar to that for surface microhardness evaluation at the baseline. These values were matched with baseline, and 7th day and 15th day for final microhardness values.

\section{Statistical Analysis}

The Statistical Package for Social Sciences (SPSS), version 20 (SPSS Inc. Chicago, IL, USA) was used to analyse the collected data. The mean of surface microhardness was evaluated statistically for all restorative groups before and after immersion in acidic drinks. Analysis of variance test followed by Tukey's post hoc test was used for statistical analysis in order to establish the significance of the differences between each group. A $p$ value of $<0.05$ was considered statistically significant.

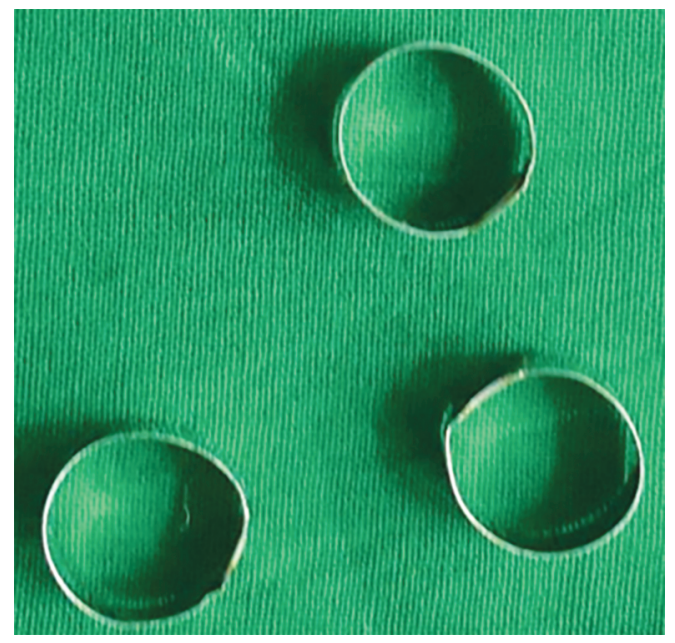

Fig. 1: Preparation of composite samples using these molds

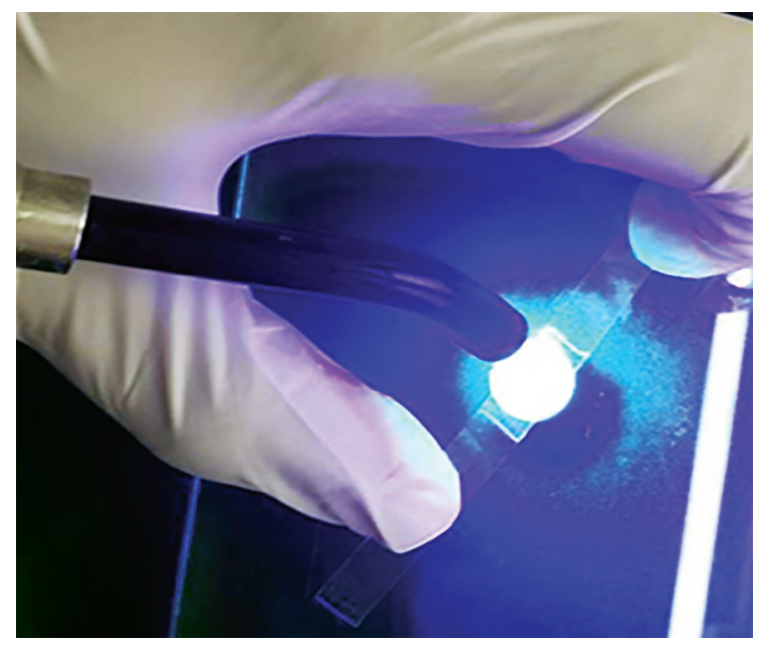

Fig. 2: LED light curing unit used to cure the composite 


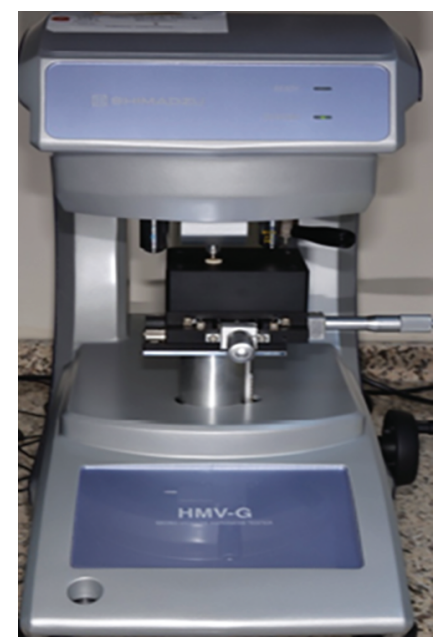

Fig. 3: Microhardness measured using a Vickers diamond intender

Table 1: Surface microhardness values of various esthetic restorative materials before the immersion into acidic drink

\begin{tabular}{lllll}
\hline Restorative materials & Mean \pm SD & Std. error & $F$ & pvalue \\
\hline $\begin{array}{l}\text { Group I: nanohybrid } \\
\text { ormocer-based } \\
\text { composite }\end{array}$ & $61.13 \pm 0.82$ & 0.1043 & 29.164 & 0.622 \\
$\begin{array}{l}\text { Group II: glasiosite } \\
\text { compomer }\end{array}$ & $59.65 \pm 1.16$ & 0.1146 & & \\
$\begin{array}{l}\text { Group III: nanoceramic } \\
\text { composite }\end{array}$ & $59.22 \pm 1.30$ & 0.0178 & & \\
\hline
\end{tabular}

Table 2: Evaluation of surface microhardness values of various esthetic restorative materials at 7th day of immersion into acidic drink

\begin{tabular}{lllll}
\hline Restorative materials & Mean $\pm S D$ & Std. error & $F$ & pvalue \\
\hline $\begin{array}{l}\text { Group I: nanohybrid } \\
\text { ormocer-based com- } \\
\text { posite }\end{array}$ & $55.78 \pm 0.16$ & 0.0132 & 28.144 & 0.001 \\
$\begin{array}{l}\text { Group II: glasiosite } \\
\text { compomer }\end{array}$ & $51.10 \pm 0.94$ & 0.2489 & & \\
$\begin{array}{l}\text { Group III: nanoceramic } \\
\text { composite }\end{array}$ & $47.68 \pm 1.30$ & 0.1639 & & \\
\hline
\end{tabular}

\section{Results}

Table 1 shows the surface microhardness values of all esthetic restorative materials before the immersion into acidic drink. A mean surface microhardness of $61.13 \pm 0.82$ was shown by group I, and this is slightly more than the mean surface microhardness of group II $(59.65 \pm 1.16)$ and group III $(59.22 \pm 1.30)$. Analysis of variance did not show statistically significant difference between the groups.

Table 2 displays the measurements of surface microhardness values of all esthetic restorative materials at 7th day of immersion. The highest reduction in surface microhardness value $(47.68 \pm$ 1.30) was found in group III after dipping into acidic drink, followed by group II $(51.10 \pm 0.94)$ and group I $(55.78 \pm 0.16)$. A statistically significant difference $(p<0.001)$ was seen between the groups.

Table 3 displays the surface microhardness values of different esthetic restorative materials at 15 th day of immersion. The lowest surface microhardness value $(46.14 \pm 0.88)$ was found in group III after 15 days of immersion into acidic drink followed by group II
Table 3: Evaluation of surface microhardness values of various esthetic restorative materials at 15 th day of immersion into acidic drink

\begin{tabular}{lllll}
\hline Restorative materials & Mean $\pm S D$ & Std. error & $F$ & p value \\
\hline $\begin{array}{l}\text { Group I: nanohybrid } \\
\text { ormocer-based com- } \\
\text { posite }\end{array}$ & $53.19 \pm 0.10$ & 0.1192 & 26.180 & 0.08 \\
$\begin{array}{l}\text { Group II: glasiosite } \\
\text { compomer }\end{array}$ & $49.87 \pm 1.02$ & 0.1477 & & \\
$\begin{array}{l}\text { Group III: nanoceramic } \\
\text { composite }\end{array}$ & $46.14 \pm 0.88$ & 0.1280 & & \\
\hline
\end{tabular}

Table 4: Multiple comparisons of surface microhardness values of various esthetic restorative materials using Tukey's post hoc test

\begin{tabular}{llcl}
\hline Groups & Compared with & Mean difference & Sig. \\
\hline Group I & Group II & 4.68 & 0.06 \\
& Group III & 8.10 & 0.001 \\
Group II & Group I & -4.68 & 0.06 \\
& Group III & 3.42 & 0.08 \\
Group III & Group I & -8.10 & 0.001 \\
& Group II & -3.42 & 0.08 \\
\hline
\end{tabular}

$(49.87 \pm 1.02)$ and group I (53.19 \pm 0.10$)$, respectively. No statistically significant difference $(p=0.08)$ was found between the groups.

The various comparisons of surface microhardness values of different esthetic restorative materials using Tukey's post hoc test are shown in Table 4. A statistically significant difference between group I vs group III was found.

The inference of the present study indicates that the nanohybrid ormocer-based composite showed relatively less effect on surface microhardness before and after being dipped in the acidic drink followed next by glasiosite compomer and nanoceramic composite

\section{Discussion}

Over the past several years, the resin-based restorative materials have been increasingly used in dentistry because of their pleasing esthetic appearance, simple handling requirements, improvements in formulations, and their ability to bond firmly to dental hard tissues. ${ }^{7}$ An ideal restorative material should offer a long-term resolution and be clinically efficacious, and this depends not just on the inherent characteristics of the material but also on the environment to which they are subjected to. Our oral cavity is an aqueous complex environment in which the restorative materials are in continuous contact with saliva. Additionally, other aspects such as reduced $\mathrm{pH}$ created by acidic drinks and foods may affect the physical and mechanical properties of the restorative material. ${ }^{8}$

Loss of dental hard tissues due to noncarious reasons has become a significant problem in the present era. Noncarious tooth lesions are only next to caries, trauma, and periodontal disease that pose threat to the function and endurance of human dentition. ${ }^{9}$ The intake of soft drinks and citrus fruits that are acidic may be the chief etiologic factor of this disease. The most significant parameter in development of tooth wear is the method and frequency of consumption of acidic foods and drinks. Thus, the intake of soft drinks along with meal is less injurious than the soft drinks consumed alone and continuous sipping is more damaging to dental hard tissues than intake of complete beverage at once. The cola beverages were found to be retained on dental enamel and are mostly not cleared by saliva when compared to other beverages, which contribute to increased cariogenicity of cola beverages. ${ }^{10}$ 
In this study, higher surface microhardness was demonstrated by nanohybrid ormocer-based composite (Admira Fusion, Voco, Cuxhaven, Germany) compared to nanoceramic composite (Ceram $X$ Universal) and Glasiosite compomer (VOCO). Unlike the results obtained by this study, Poggio et al. ${ }^{11}$ found an initial hardness of $57 \mathrm{HV}$ associated with nanoceramic composite (Ceram X Universal) (less than this study, and the initial values of Admira); however, it can avoid acid attack effectively. Lastly, good initial value of microhardness was shown by the nanohybrid ormocer-based composite (Admira Fusion) and it did not display a significant loss of microhardness after being soaked in soft drink for a week.

Rizzante et al. ${ }^{12}$, Thomaidis et al. ${ }^{13}$, Baeshen et al. ${ }^{14}$ have demonstrated a low microhardness value $(37.36 \pm 5.15)$ for ormocerbased composite. The differences in the matrix for Ormocer ${ }^{\circledast}$ ceramics that are modified organically (linking of organic polymers with inorganic matrix, instead of methacrylate based) along with its changed filler content (based on silicon oxide only) may contribute for the differences in microhardness values.

It has been shown by Cavalcante et al. ${ }^{15}$ that regardless of the material used, light exposure mode does not affect the immediate microhardness values. Largely, irrespective of material exposure mode or storage media did not significantly affect microhardness after 1 week of storage. The microhardness values increased after 1 week of dry storage comparative to immediate testing for all materials and decreased after ethanol and water storage, with ethanol displaying the highest effect. The investigational ormocer-based material had the lowermost percentage change in microhardness irrespective of the light-exposure method and thus shown to be further resistant to degradation by solvents than the other materials.

We selected Vickers microhardness test as it is fairly a simple technique, very common, and reliable method for obtaining the results. Furthermore, according to Leung et al. ${ }^{16}$, Marghalani et al. ${ }^{17}$, this test is commonly used as an indirect method to assess the degree of polymerization cure and have considered it as an indicator for the degree of polymerization of resin materials. The surface microhardness is associated with the rigidity of material and is considered an indicative aspect of the resin's mechanical strength.

In this study, Coca-Cola was the acidic drink that was used and samples were dipped for 10 minutes in $25 \mathrm{~mL}$ of acidic drink every day for 15 days. After immersion, the highest decrease in surface microhardness was seen in first seven days. Al-Taie et al. ${ }^{18}$ demonstrated that the integrity of resin composite materials gets significantly affected after 60 days of exposure to soft drinks. The composite resins with lower filler volume and larger filler particle size are probably more susceptible to degradation in environments that are acidic. Prakki et al. ${ }^{19}$ identified that ester groups present in the resin matrix hydrolyze to form more carboxylic groups and this reaction rate is affected by $\mathrm{pH}$, and these carboxylic groups contribute to additional lowering of the $\mathrm{pH}$ within the polymeric matrix. As found by Narsimha et al., ${ }^{20}$ both microhardness and marginal integrity of restorative materials get invariably affected after prolonged contact with acidic media, and they established that the surface breakdown and marginal integrity of the investigational restorative material are directly related to the rate of acidic drink exposure.

The restriction of the present study was that in an in vitro environment the decrease in the microhardness of a restorative material may lead to its breakdown or deterioration. However, composite resin materials may be exposed to different chemical agents found in beverages and food items either continuously or discontinuously under in vivo conditions. Subsequently, these conditions may have an altered harmful effect on the network of polymers in the short- or long-term, thus modifying its chemical and physical structure.

\section{Conclusion}

The surface microhardness of restorative materials significantly reduced when exposed to acidic drinks on a regular basis. The present study accomplishes that the esthetic restorative material-nanohybrid ormocer-based composite-showed the finest behavior both before and after being dipped in the acidic drink followed by glasiosite compomer and nanoceramic composite.

\section{References}

1. Veena Kumari R, Pradeep PR, Aswathi S, et al. Evaluation of surface roughness of composite resins with three different polishing systems and the erosive potential with apple cider vinegar using atomic force microscopy-an in vitro study. Acta Sci Dent Sci 2019;3(3):08-16.

2. Nasim I, Neelakantan P, Sujeer R, et al. Color stability of microfilled, microhybrid and nanocomposite resins - an in vitro study. J Dent 2010;38(Suppl 2):e137-e142. DOI: 10.1016/j.jdent.2010.05.020.

3. Aguiar TR, Gaglianone LA, Mathias P. An overview of the impact of lifestyle behaviors on the operative dentistry. J Interdiscipl Med Dent Sci 2014;2:128.

4. Silva KG, Pedrini D, Delbem AC, et al. Effect of $\mathrm{pH}$ variations in a cycling model on the properties of restorative materials. Oper Dent 2007;32(4):328-335. DOI: 10.2341/06-89.

5. Çökük N, Kaki GD, Recen D, et al. The effects of pH changes on the microhardness of three fluoride releasing restorative materials: an in vitro Study. EC Dent Sci 2018;17(9):1645-1651.

6. Yanikoğlu N, Duymus ZY, Yilmaz B. Effects of different solutions on the surface hardness of composite resin materials. Dent Mater J 2009;28(3):344-351. DOI: 10.4012/dmj.28.344.

7. Erdemir U, Yildiz E, Eren MM, et al. Surface hardness Evaluation of different composite resin materials: influence of sports and energy drinks immersion after a short-term period. J Appl Oral Sci 2013;21(2):124-131. DOI: 10.1590/1678-7757201302185.

8. Okada K, Tosaki S, Hirota K, et al. Surface hardness change of restorative filling materials stored in saliva. Dent Mater 2001;17(1): 34-39. DOI: 10.1016/S0109-5641(00)00053-1.

9. Hooper S, West NX, Pickles MJ, et al. Investigation of erosion and abrasion on enamel and dentine: a model in situ using toothpastes of different abrasivity. J Clin Periodontol 2003;30(9):802-808. DOI: 10.1034/j.1600-051X.2003.00367.x.

10. Kaur S, Makkar S, Kumar R, et al. Comparative evaluation of surface properties of enamel and different esthetic restorative materials under erosive and abrasive challenges: an in vitro study. Indian J Dent 2015;6(4):172-180. DOI: 10.4103/0975-962X.165047.

11. Poggio C, Viola M, Mirando M, et al. Microhardness of different esthetic restorative materials: evaluation and comparison after exposure to acidic drink. Dent Res J 2018;15:166-172. DOI: 10.4103/1735-3327.231863.

12. Rizzante FAP, Duque JA, Duarte $M A H$, et al. Polymerization shrinkage, microhardness and depth of cure of bulk fill resin composites. Dent Mater J 2019;38(3):403-410. DOI: 10.4012/dmj.2018-063.

13. Thomaidis S, Kakaboura A, Mueller WD, et al. Mechanical properties of contemporary composite resins and their interrelations. Dent Mater 2013;29:132-141. DOI: 10.1016/j.dental.2013.04.025.

14. Baeshen $\mathrm{H}$, Alturki BN, Albishi WW, et al. Mechanical and physical properties of two different resin-based materials: a comparative study. J Contemp Dent Pract 2017;18:905-910. DOI: 10.5005/ jp-journals-10024-2147. 
15. Cavalcante LM, Schneider LF, Silikas N, et al. Surface integrity of solvent-challenged ormocer-matrix composite. Dent Mater 2011;27:173-179. DOI: 10.1016/j.dental.2010.10.002.

16. Leung $R$, Fan $P$, Johnston W. Post-irradiation polymerization of visible light-activated composite resin. J Dent Res 1983;62(3):363-365. DOI: 10.1177/00220345830620031201.

17. Marghalani HY. Post-irradiation Vickers microhardness development of novel resin composites. Mat Res 2010;13(1):81-87. DOI: 10.1590/ S1516-14392010000100017.
18. Al-Taie LA, Al-Aubaydi AF, Al-Shamma AM. The effect of pepsi cola beverage on surface roughness of two composite resins (in vitro study). 2010;7(1):9-14.

19. Prakki A, Cilli R, Mondelli RF, et al. Influence of $\mathrm{pH}$ environment on polymer based dental material properties. J Dent 2005;33(2):91-98. DOI: 10.1016/j.jdent.2004.08.004.

20. Narsimha VV. Effect of cola on surface microhardness and marginal integrity of resin modified glass ionomer and compomer restoration-an in vitro study. People's J Scientific Res 2011;4(2):34-40. 